\title{
Helping Orphaned and Vulnerable Children to Manage Cognition and Learning Crises through Policy: The Case of Zimbabwe
}

\author{
Emily Ganga \\ Great Zimbabwe University, Faculty of Education, Department of Educational Foundations, \\ PO Box 1235, Masvingo, Zimbabwe \\ E-mail: emilyganga@gmail.com \\ MC Maphalala \\ University of South Africa, College of Education, Department of Curriculum \& Instructional Studies, \\ PO Box 392, Unisa, 0003, South Africa \\ E-mail:mphalmc@unisa.ac.za
}

\section{Doi:10.5901/mjss.2014.v5n1p439}

\begin{abstract}
This qualitative enquiry tried to find out ways in which policy could further assist orphans and vulnerable children to manage their cognition and learning crises. It is based on the policy issues of the Zimbabwe National HIV and AIDS Strategic Plan (ZNASP, 2006-2010), the National Action Plan for Orphan and Vulnerable Children (NAP for OVC 2006-2010), the Zimbabwe Education Act (Chapter 25:04) and the Zimbabwe Millennium Development Goals (2004). The triangulated data were collected through participant observations, open-ended questionnaires, interviews and focus group discussions held at four secondary schools. The purposefully selected participants comprised 20 double orphans and vulnerable children, four headmasters, eight teachers, one Education Officer and one Social Welfare Officer, making a total sample of 34. The findings confirmed that even though some OVC reported occasional receipt of aid through donors and the government's facilities such as the Basic Education Assistance Module (BEAM), not all OVC were lucky enough to remain beneficiaries up to the end of their secondary schooling. Orphanhood was found to be a psychological deterrent to cognition and learning. Therefore the local community, education administrators, policy makers, and children's rights advocates together with the children's representatives should map out life lines ideal for enhancing the cognitive learning of double OVC residing in $\mathrm{CHH}$.
\end{abstract}

Keywords: orphanhood, child-headed household, orphans and vulnerable children, learning, cognition, policy

\section{Background}

The human immunodeficiency virus and acquired immunodeficiency deficiency syndrome (HIVIAIDS) pandemic has brought about multiple deaths within most Zimbabwean families, leaving many schoolchildren orphaned and vulnerable. The growing trend (orphanhood) seems to be perpetuating the mushrooming of child-headed households ( $\mathrm{CHHs}$ ) where some school-going orphan and vulnerable children (OVC) were observed opting to reside on their own, resulting in both positive and negative interferences in their cognition and learning. In their $\mathrm{CHHs}$, older OVCs share parental roles in addition to their own roles as schoolchildren. They were often reported to sometimes fail cognitive tasks, absent themselves from school more often than other children and in serious situations have dropped out of school even when on the Basic Education Assistance Module (BEAM) funding. This study investigated how policy may assist in the enhancement of cognition and learning of OVCs living within child-headed households. The results of this study helped to establish means of empowering OVC with learning skills to help them cope in their $\mathrm{CHHs}$.

The researchers hope that the results of this study would help to establish means of empowering OVC with learning skills that help them to cope in their $\mathrm{CHHs}$. The research outcomes also benefited not only the orphans but also the policy makers, policy implementers, curriculum planners, the schools, local communities, the law enforcers, advocates of orphans and vulnerable children, and teachers as well as potential orphans in establishing favourable ways of assisting in the learning and cognition of OVC. The government, through its various ministries, could also help to emancipate the orphan, reduce academic and psychological exploitation of minors and perhaps take much more seriously the plight of orphaned learners countrywide.

Therefore this study endeavoured to join hands with all children advocates in trying to establish the best ways of 
normalising family life, learning and cognition in $\mathrm{CHHs}$.

\subsection{Research question}

How can the schools, local communities and policy makers be academically and emotionally prepared to assist orphaned children to achieve their intended learning goals?

\subsection{Objective of the study}

To establish how the schools, local communities and policy makers can be academically and emotionally prepared to assist orphaned children to achieve their learning goals.

\section{Policy Issues}

\subsection{The Zimbabwe National HIV and AIDS Strategic Plan (ZNASP 2006-2010)}

The policy issues covered in the Zimbabwe National HIV and AIDS Strategic Plan (ZNASP, 2006-2010), the National Action Plan for Orphan and Vulnerable Children (NAP for OVC 2006-2010), Chapter 25:04 of the Zimbabwe Education Act and the Zimbabwe Millennium Development Goals (MDGs) (2004) ascertain that the main root cause of orphan crises that led to the mushrooming of $\mathrm{CHHs}$ in most sub-Saharan African countries was the HIVIAIDS pandemic. It is assumed that policy may assist in efforts to enhance the learning and cognition of OVC in difficult life circumstances.

According to the ZNASP (2006-2010), it is now two decades since the first AIDS case was reported in Zimbabwe (ZNASP, 2010). Though a decline in HIV prevalence has been recorded from 26 to 18,1\%, the number of orphans and vulnerable children remains alarming. The President of Zimbabwe reiterated the need to note emerging challenges encountered due to the rise in OVC. To this end a National Plan of Action or Policy for OVC was established to mitigate the impact of HIVIAIDS on OVC. At the time of writing this thesis the 2006-2010 OVC policy was under review.

The theme of the ZNASP is based on a commitment that should be put into action by both the government and all stakeholders involved in issues of HIVIAIDS. The ZNASP (2006-2010) specifies, among other roles for researchers and consultants, the preparation of working documents and analysis to help focus on key issues at various stages of the strategic process (ZNASP 2006-2010). This study therefore attempts to join all other advocates of better education for OVC by focusing on the effects of orphanhood, where children reside alone as siblings in $\mathrm{CHHs}$. The researchers hope to make meaningful contributions to the Government of Zimbabwe (GoZ) and other stakeholders on how learning of OVC, especially double orphans, can be enhanced in CHHs. Presently, Zimbabwe falls among the many southern African countries where it is part of the epicentre of the HIVIAIDS pandemic (UNICEF, 2007).

In Zimbabwe the label "orphan" captures a number of influencing vulnerability factors that can deter cognition and learning. Children with some unfulfilled rights are included as orphans in the ZNASP (2006-2010). These vulnerability factors according to the ZNASP (2006-2010:2) include children with one parent, children with disabilities, children affected and infected by HIVIAIDS, abused children (sexually, physically and emotionally), working children, destitute children, abandoned children, children living on the streets, married children, neglected children, children in remote areas and children with chronically ill parents.

All of the above require the attention of GoZ ministries, especially that of education, of nongovernmental organisations and many other advocates of children's rights, in order for each child to accomplish his or her life line and education goals. The study, however, delimits the lot of vulnerable children to studying the effects of orphanhood on the cognition and learning of double orphans residing in $\mathrm{CHHs}$. Most of the double orphans observed within the district carry many of the attributes highlighted above. One OVC, for instance, may carry double orphanhood, HIVIAIDS, could be working, neglected, and caring for terminally ill parents. It is assumed that the extent of orphanhood has some effects on the learning and cognitive processes of any learner, including OVC. There is need to enquire more into these issues in order to establish the best ways of enhancing the learning of OVC, especially those heading $\mathrm{CHHs}$ who may at times act out parental roles without much experience or guidance.

About 19\% of the 1,3 million child's population in Zimbabwe is orphaned by AIDS (UNAIDS, 2010). Current surveys countrywide estimate that about $30 \%$ of the child population in rural and high-density urban Zimbabwe are orphans (ZNASP, 2006-2010). The impact of the pandemic goes beyond families and communities to commerce, industry, health services and education because life expectancy has been greatly reduced (UNICEF Global Estimate, 
2004).

Presently, mitigation strategies include programmes to support OVC in as far as food and nutritional support in $\mathrm{CHHs}$ and women-headed households where there are chronically sick family members. As such, the launch of the National Action Plan for Orphans and other vulnerable children (NAP for OVC, 2006-2010) in 2005 became a significant milestone for mitigation against the impact of HIV in Zimbabwe. With the aim of reaching at least $25 \%$ of OVC (USAIDS, 2010) through educational, medical, legal and psychosocial assistance, this study endeavours to join partners in the multisectoral response by identifying the effects of orphanhood on the metacognition processes of OVC so that any interventions become more meaningful and are directed towards truly needy OVC, such as the double orphan.

OVC fall among many high-risk groups, which includes challenges in receiving ideal educational opportunities (Chinyoka \& Ganga, 2011). It has been noted that $20-30 \%$ of the registered OVC are receiving some kind of assistance. Many fall within the hard-to-reach populations (NAP for OVC, 2006-2010) who are often excluded from aid. For instance, the ZNASP (2006-2010:14) mentions the fact that children have largely been excluded from the antiretroviral therapy (ART) rollout programmes. This study will try to implement ZNASP evidence- and results-based strategies through rigorous procedures by working with OVC as participants in the enquiry. USAIDS (2010) mentions through the ZNASP that operational research will be necessary if Zimbabwe is to more closely identify the needs of OVC. This may be possible through working with regional and international HIVIAIDS initiatives such as conventions which include the Millennium Development Goals (Zimbabwe Millennium Development Goals, 2004), the United Nations General Assembly on HIVIAIDS, and many others that aim to ensure the goals set are achieved.

Among the key strategies and targets of the ZNASP is the need to consolidate and expand the in-school life skills programmes where the Zimbabwe Ministry of Education, Sports, Arts and Culture (MoEASC) is making efforts to finalise a life skills strategic plan (ZNASP, 2006-2010). All young people are to benefit from this strategic plan, including OVC in CHHs.

In addition to the above, specific needs of OVC will be dealt with through equitable accessibility of OVC to the Basic Education Assistance Module (BEAM), National Aids Trust Funds (NATF) and external funds available to the National Plan of Action for OVC. According to the ZNASP (2006-2010:25), programmes will include the provision of basic health and social services, including schooling, administrative assistance and shelter.

Above all, the ZNASP places great importance on evidence-based interventions to ensure initiatives are demanddriven and relevant. These researchers joined hands with other stakeholders in the multisectoral response, led by the NAC, in contributing to studies, reviews, assessments and research that will become necessary from time to time in the areas of HIVIAIDS covering prevention, treatment, care and support (Zimbabwean Demographic Health Survey, 20052006). This study views support and care issues as vital aspects in research that concern orphaned children. This part of the research on the marginalised and most-at-risk groups in Zimbabwe forms one part of the seven recommended areas of research by the ZNASP (2006-2010).

If the learning needs of OVC are established and appropriate intervention rendered, perhaps the Zimbabwean National AIDS Council can be able to realize its second goal i.e. to improve quality of life for infected and affected. OVC in CHHs may not all be infected by the virus but obviously are affected by the ravaging effects of the pandemic. Learning and cognitive need research may help as an intervention strategy so as to provide appropriate care and support necessary to children in distress.

\subsection{The National Action Plan for Orphans and Vulnerable Children (NAP for OVC)}

The NAP for OVC by the Ministry of Labour and Social Services was started in 2003 in response to the challenges faced by increasing numbers of OVC in Zimbabwe (NAP for OVC, 2006-2010). In line with the ZNASP, the vision of the NAP for OVC is to reach out to all OVC in Zimbabwe with basic services that positively impact on their lives. The NAP for OVC (2006-2010) document has two versions to include a simpler child-friendly version intended for affected children.

In the NAP for OVC child-friendly version (2009:13-15) the major focus is on education of children where it promises an increase in the number of children who go to primary and secondary school. The NAP for OVC was developed to include the situation of children living with the disadvantages of HIVIAIDS, with a lack of resources to respond and of many but only fragmented interventions (NAP for OVC, 2006-2010). Noted were opportunities for a policy and legislative framework for child care and protection. The NAP for OVC was built on opportunities such as the MDGs and the UN General Assembly Special Session (UNIGASS) on HIVIAIDS goals 65, 66 and 67.

In line with the ZNASP (2006-2010), the Rapid Assessment, Analysis and Act Planning Process (RAAAPP, 2004) for OVC suggested that the situation of OVC in Zimbabwe is an increasing threat to socioeconomic development. Even 
though there seem to be a number of organisations providing aid to OVC, very little is known about the resources available, number of children reached and geographical coverage of the services (NAP for OVC, 2006-2010).

To support children, the GoZ has two key national policies and a legal framework that supports children. Legislation for children includes the Children's Act (Chapter 5:06), the Guardian of Minors Act, Education Act, Maintenance Act, the Child Abduction Act and many other statutes focusing on children. The NAP for OVC, for instance, uses child-friendly language (2009:13-15) that clearly states to children that every child is promised an opportunity for schooling.

The national policies include the Zimbabwe National Orphan Care Policy (ZNOCP, 1999) and the NAP for OVC (2006-2010). The two policies reflect Zimbabwe`s strengths in traditional ways of caring for children at community level. However, due to other variables, there seems to be a paradigm shift in which after the loss of parent the children themselves are opting to stay alone in a $\mathrm{CHH}$. While more and more children are opting to reside in $\mathrm{CHHs}$, the ZNOCP recognises the traditional leader's role in the care and the significance of supportive programmes such as ZundeRamambo/InsimuyeNkosi and Dura Ramambo//siphelaseNkosi (Chief's Granary) that is known to provide food security to all marginalised and poor groups within the community (NAP for OVC, 2006-2010).

The NAP for OVC in Zimbabwe defines OVC from a variety of factors that influence vulnerability. Besides looking at those whose parents have died, the ZNOCP and NAP extend the definition to children who have unfulfilled rights. The policy makes little mention of types of orphans such as "single" and "double" orphans and orphanhood as just one portion of vulnerability; yet many children fall into numerous categories that communities identify. See categories listed by the ZNASP (2006-2010) under 2.4.1. It is however pleasing to note that the NAP for OVC budget for 2006-2010 included quite high budgets for education of children among other expenditures. The funds, managed by UNICEF, are mobilised through Programme Support (PS) mechanisms from varied international donors, namely the DFID (UK), New Zealand AID, SIDA (Sweden), Germany's CFW, Australia's AID and the European Commission (NAP for OVC, 2006-2010). This study assumes that, once the learning needs of OVC are fully understood by every stakeholder, the rightful beneficiaries of the NAP funds may then be assisted.

Some guidelines for the NAP were developed by GoZ ministries and the National AIDS Council in liaison with UNICEF, the DFID and SIDA (NAP for OVC, 2006-2010). The guidelines help to specify roles and responsibilities of key institutions involved in the management, disbursement and use of mobilised resources. So the NAP for OVC is a programme that is being implemented collaboratively, while PS is the vehicle through which resources are mobilised to support programme implementation. Clear-cut goals, objectives, purpose and principles are specified by the ZNOCP in the NAP for OVC (2006-2010:5-6). Once the learning needs of OVC are stipulated by OVC themselves then it may be possible for stakeholders to reach out and assist in enhancing the learning and cognition of orphaned children.

The organisational structure of the NAP for OVC has a hierarchical structure that draws from the state and the government cabinet, from the national, provincial and district levels, as well as from the community level. Each component has its own task (NAP for OVC 2006-2010:7). The implementation modality is double-barrelled, covering state and non-state sectors. State sectors are governed ministries such as the MoEASC, while non-state sectors are organisations registered with authorities and are implementing programmes for child care. In this basis, UNICEF is responsible for the release of funds and managing it.

As far as research is concerned, the NAP for OVC document encourages both quantitative and qualitative procedures, but more for the later procedures, because of its ability to make stakeholders understand both positive and negative processes, outputs, outcomes and policies during implementation (NAP for OVC, 2006-2010).

In addition, the OVC policy document encourages qualitative research since it focuses on unique knowledge, competencies, capabilities and so on --- hence the idea of embarking on this phenomenological case study. When all these outcomes are combined, the information may lead to better understanding of what stakeholders can do to improve OVC programmes and suggest the best procedures to implement. This study, taking more from qualitative procedures, endeavours to work in line with the NAP for OVC policy initiatives for the situation of double orphans operating in $\mathrm{CHHS}$ in Chipinge, Zimbabwe. Perhaps findings will recommend appropriate intervention in education to ensure enhanced learning for OVC in CHHs. The NAP for OVC (2006-2010:15) encourages institutions with capacity and research experience to undertake operational research (OR) in an effort to help the child at risk or one living in difficult life circumstances.

The child-friendly version of the NAP for OVC (2006-2010) endeavours to help OVC understand all intervention procedures, all children's rights, how and where to get aid in a number of areas, issues of abuse, and of education, including a number of government and nongovernment plans for all OVC. It is pleasing to note that the child-friendly version of the NAP for OVC was worked out with many child representatives from a number of child-run organisations in 
Zimbabwe, hence the note by child representatives in the document that "anything for us, without us, is against us". So Zimbabwe has taken heed of Nelson Mandela's dictum in the NAP child-friendly version (2006-2010:1) that "there can be no keener revelation of society's soul than the way in which it treats its children".

\subsection{Zimbabwe's Millennium Development Goals and the Education Act (Chapter 25:04)}

The Education for All (EFA) movement aims to provide quality education for all children irrespective of their socioeconomic background, culture or creed (Dakar Framework of Action, 2000). A total of 164 governments including Zimbabwe met at the World Education Forum in Dakar, Senegal, where they pledged to achieve quality EFA; six goals were identified and all governments agreed to achieve these by year 2015. As in any other nation, the GoZ is working hard to achieve these goals towards which UNESCO was mandated to coordinate the UNDP, UNICEF and the World Bank. According to the Dakar Framework of Action (2000), UNESCO focuses on five key areas, covering policy, monitoring, advocacy, mobilisation of funds and capacity development.

The six EFA goals aim to meet the learning needs of all children and even adults by 2015 (Dakar Framework of Action, 2000). Among the children mentioned were OVC in CHHs who need special guidance in the absence of adults and parents. In fact, the older OVC stand on their own as parents for the younger ones within a $\mathrm{CHH}$. In the area of expanding and improving early child care and education (Goal 1) many who are OVC because of the AIDS pandemic remain vulnerable and may fail to receive appropriate formal or informal schooling. Goal 2 focuses mainly on educating children, especially girls, in difficult life circumstances, including OVC belonging to various ethnic groups. Quality, free compulsory education is a prerequisite but the issue of fees becomes a hindering factor. Education is not free for all unless one is lucky and enrolled under BEAM or NTTF, where a portion of school fees is catered for (Jinga \& Ganga, 2011). The number of items to be provided freely by BEAM may not cover all OVC needs for learning and survival.

Goal 3 of the EFA focuses on meeting the learning needs of all children and adults through equitable access to basic and continuing education for all. The idea of aiming to achieve at least 50\% improvement in adult literacy by 2015 , especially in women, allows young mothers, including OVC possibly disadvantaged by early pregnancies, to complete their schooling and become literate. This aim was noted by Ganga and Chinyoka (2011) as they explored the psychological disorders caused by poverty among OVC. The idea of eliminating gender disparities, as in Goal 5, augments Goal 4 in favour of young women who may have been abused, become pregnant and then forced to leave school early. They can also have access to basic education. The final goal, Goal 6 , reminds nations of the importance of improving all aspects of quality education to ensure excellence and recognition of all learning outcomes in areas of numeracy, literacy and life skills.

Though BEAM funding may be overwhelmed (Zimbabwe National Aids Council, 2011), the GoZ (Zimbabwe National Aids Council, 2011) endeavours to take heed and educate the populace including marginalised children like OVC. The 2004 Zimbabwe Millennium Development Goals progress report endeavours to adapt the eight MDGs adopted by the fifty-fifth session of the United Nations Assembly to the capacities, values and aspirations of the population (Zimbabwe Millennium Development Goals, 2004).

The progress report on MDGs is the response to the UN series of world summits and global conferences aimed to lay out a rights-based development agenda. Again, Zimbabwe was among the 189 heads of state and governments who agreed on the Millennium Declaration at the Millennium Summit of September 2000. Among the MDGs were issues related to education as well as health, HIVIAIDS, gender equality and other matters concerning the welfare of Zimbabweans. The goals focused mainly on providing developmental challenges to governments and various stakeholders. The report emphasises collaboration on both implementation and monitoring of MDGs. The issue of developmental challenges within the MDGs encompasses the OVC predicament that requires intervention and close monitoring by all stakeholder representatives if family life and education are to survive following the loss of a parent or parents.

Each of the eight MDGs seems to cater for OVC, whose education may be impaired or lost if stakeholders do not keep a watchful eye. For instance there is interconnectivity in the functioning of the eight goals to the learning and cognition of OVC, for example the need to eradicate extreme poverty, as in MDG 1, in order to allow MDG 2 to help OVC complete their universal primary education. Since most OVC in $\mathrm{CHHs}$ are from parents who died of HIVIAIDS it becomes prudent to consider MDG 6, which aims to combat HIVIAIDS and other related diseases. Once OVC in CHHs are made aware of the consequence of faulty sexual practices, their learning and cognition may run smoothly and ensure achievement of MDG 7, which stipulates environmental sustainability. Any psychological disturbances in OVC's metacognition may have detrimental effects on them if their learning needs and lifestyles are not monitored from time to 
time. This study, therefore, attempts to pick up some of these effects of orphanhood on the learning of OVC residing in Zimbabwe's CHHs, all in an effort to find the best ways to liberate OVC and shape a better life line for them.

The Education Policy in Zimbabwe tries to follow EFA goals as well as the prescribed MDGs that do not segregate children. According to Chapter 25:04, 26/1991, 24/1994, of the Zimbabwe Education Act, a child of school-going age is one of an age within such limits as many may be described. In other words the Act does not prescribe a specific age but may consider all learners, for as long as they are still in school. Part 2 of the Education Act specifies fundamental rights and objectives for education in Zimbabwe. First and foremost, every child in Zimbabwe shall have the right to school education. Admission does not segregate in any manner, including social status of parents. Each parent should ensure that his or her child attends school. Perhaps at the time of framing this Act there were not many child-parent families, as there are today: hence the need for constant review of the Act and research involving the affected OVC.

A number of educationists and researchers are presenting research studies on EFA goals, MDGs and the area of HIVIAIDS, but little has been documented on the phenomenology of OVC and learning in Zimbabwe. In an assessment of the efforts towards attainment of education for all (EFA) in Zimbabwe as agreed at the World Conference on Education for All (WCEFA), held in Dakar, Senegal, in 2000, Mavhunga, Madondo and Phiri (2009) advise on the need to take stock of progress and to increase access to education for previously marginalised Zimbabweans. They noted an increase in school fees, the economic downturn and ravaging effects of HIVIAIDS that left children orphaned. More research is therefore needed on OVC and learning in Zimbabwe.

\section{Research Methodology}

\subsection{Ethical considerations}

This study aimed at constructing a social reality on the ecological encounters of OVC in CHHs. Being a sensitive study, a number of ethical considerations took precedence in order to protect OVC, the researcher, teachers, and government and nongovernmental stakeholders involved. The ethical considerations included issues of confidentiality, autonomy, beneficence and nonmaleficence of human research participants as stipulated in the Unisa Policy on Research Ethics (2007).

The status of the major participants, which was orphanhood, raised attitudinal fears that would have inhibited orphans from becoming participants in this study. An effort was made to allow the participants to go through some individual and group psychosocial counselling in which the major purpose of the study was explained. The issue of signed consent and assent forms remained vital from the beginning.

\subsection{The research design}

This study fell within a qualitative research paradigm. The researchers employed a phenomenological descriptive case study. The major intention in phenomenology is to comprehend phenomena through descriptions of human experiences by the subjects experiencing conscious, social experiences (Creswell, 2007); in this case OVC in CHHs are allowed to tell their experiences as far as cognition and learning are concerned. The teachers and headmasters working with them most of the time assisted in observations that aimed to authenticate learning experiences presented by OVC.

As guided by Schram (2006) and Yin (2003), the case study design has the ability to adapt to a wide range of frameworks such as that of phenomenology in which it strives to describe, analyse and interpret the developmental encounters that affect the learning and cognition of OVC in $\mathrm{CHHs}$. It endeavoured to explore and present an authentic situation on the developmental and learning experiences of OVC. This case study was an exploration of a bound system involving multiple cases over a period of time through detailed, in-depth data collection involving multiple sources of information from varied data collection tools as well as the purposefully selected participants (Creswell, 2007).

\subsection{Sampling the participants}

Four secondary schools were purposefully chosen because it was noted that the greater number of OVC found in these schools were from CHHs. In each of the four schools (2 rural and 2 urban), five double orphans (making a total of 20), the school head (4 in all), two teachers (8 in all), one District Education Officer and a Social Welfare Officer were purposefully selected to make a total sample of 34 participants. The idea of purposeful sampling was to obtain the most characteristic representation of attributes that served the purpose of the study (Grinnell \& Unrau, 2008). The sample in 
this qualitative case study, 34 participants, was small and mainly meant to allow participants to give their life experiences (Rubin \& Babbie, 2008).

\subsection{Data collection}

Prior to visiting the schools and $\mathrm{CHHs}$, the researchers obtained permission to do research in the Chipinge district. Some senior GoZ ministry authorities had to be consulted. After having obtained research permission and consent from the Chipinge District Administrator at the Chipinge Local Government Offices, the researchers also sought consent from the Secretary of the MoEASC at the Zimbabwe MoEASC head office and the education director at the provincial office, as well as from the education officers at the MoEASC Chipinge district offices. Permission was granted without any challenges.

Numbered alphabet codes were used to identify each of the 34 participants at each data collection venue. Openended questionnaires and interviews, focus group discussions and observations were used to collect data that was needed to find out the developmental and learning experiences of OVC living in $\mathrm{CHHs}$.

\subsection{Data analysis plan}

For data analysis, more of the thematic procedures (O'Neil, 2011), involving cross-tabulations, descriptions, narratives, anecdotal records, vignettes and other manual procedures, were augmented by use of a Tesch's qualitative data analysis tool coined by Tesch (1990) in Creswell (2002). The procedures here occurred simultaneously with data collection and interpretation (Creswell, 2007). This led to reduction of data and creation of particular codes and clues for themes to follow in presenting the qualitative findings.

\section{Research Findings}

Fifteen (15) OVC (i.e. BR6-DR20) belonged to rural secondary schools while five (5) OVC (AU1-AU5) belonged to urban secondary schools. All the 20 OVC were literate and attending school (Form 2-5) within their locality. Most of their parents had some liabilities and had left no useful assets for their children besides either a house or hut(s) of two to four rooms. Codes AUS21 up to DRS32, US33 and US34 are pseudonyms of the14 stakeholders involved.

\subsection{The results}

Theme: improving policy, preparing OVC and the communities to assist orphaned children to accomplish their intended life-line goals

Figure 1: Preparing OVC and communities for OVC aid to OVC's life-line goals

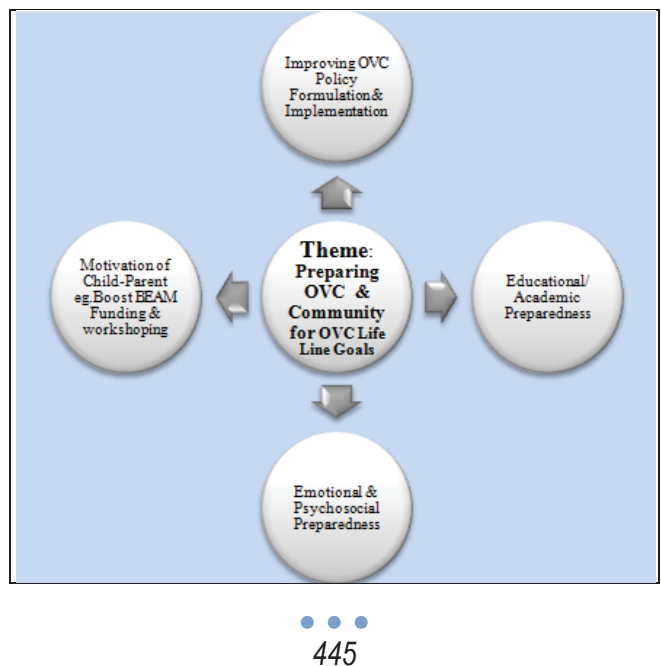


We refer to Figure 1 above indicating ways in which OVC and the rest of the community can be prepared to allow OVC some pathways to achieve their life-line goals. The fact that policy issues covered in the ZNASP (2006-2010), the significance of the NAP for OVC, the Zimbabwe Education Act (Chapter 25:04) and the Zimbabwe MDGs was noted for dealing with OVC, because each included the welfare of orphans and vulnerable children. The number of OVC remains the same even if a decline in HIVIAIDS prevalence was recorded in Zimbabwe, from 26 to 18,1\%. Therefore it became prudent for the NAP for OVC to establish ways of mitigating the impact of HIVIAIDS on OVC.

By interacting with the 14 stakeholders in this study, we noted the commitment to help OVC from both government and nongovernmental organisations because earlier researchers (UNAIDS, 2010) had established that Zimbabwe falls among the many southern African countries which are part of the epicentre of HIVIAIDS. The basic vulnerability factor picked for this qualitative enquiry was double orphanhood. It was noted from the voices of the 34 participants that double orphanhood was a devastating situation faced by many minors mainly due to the ravaging effects of HIVIAIDS, which has not spared any race or either gender. Its effects on children have moved from a relatively less serious loss of family resources to the immense suffering of minors, especially as far as learning and cognition were concerned.

\subsection{Sub-category 1: Improving OVC policy formulation and implementation}

All the 14 adult stakeholders agreed that policy can help the general populace to plan and implement the best ways to support the learning of suffering children. If surveys through the ZNASP (2006-2010) claim that the 30\% of the child population in rural and high-density urban Zimbabwe are orphans, then the launch of the NAP for OVC in 2005 was a noble mitigation strategy on the impact of HIVIAIDS in Zimbabwe. The pandemic goes beyond families and communities, and even beyond education. All 14 stakeholders stood by the idea that if policies were to prepare OVC and communities fully, then the MoEASC "in school life skills programmes" should definitely be finalised so that all young people and OVC from $\mathrm{CHHs}$ would benefit. They also added that BEAM and NATF assistance intended for children would require reassessment so that the intended beneficiaries of the funds can gain access.

If all learning needs of OVC are carefully investigated, as in this enquiry, then it would be easier to effect appropriate mitigation strategies for OVC. The sections that follow tried to establish the best ways to prepare stakeholders for intervention into the learning of OVC so as to minimise any negative effects of double orphanhood on the learning and cognition of the learner. We noted in this phenomenological study that the majority of OVC we interacted with in this enquiry were among the "hard-to-reach populations" (NAP for OVC, 2006-2010) who were often excluded from aid. This is because only two out of 20 OVC involved as study participants were believed to be receiving full aid in their learning. Others hinted that they used to receive aid from the Farm Orphan Support Trust of Zimbabwe (FOST) but were removed from the roll of beneficiaries without prior notice. Therefore it is vital that stakeholders find ways in which all community members are prepared to help orphaned children learn better.

It was vital to first re-check the missing cognition and learning needs that the orphans presented in Theme 4, under figures 15 and 16 . The requirements noted by the 14 stakeholders matched those mentioned by the 20 OVC. The lengthy list included material needs in the form of food, stationery, clothing, shelter, school fees, and so on, as well as psychological needs including security, motivation, parental guidance and care, moral support, love and empathy. The rather sad notion learnt from OVC's pleas for need gratification was the fact that lack of these needs culminated in psychological drawbacks such as lack of concentration in school work by the affected children.

On responding to a question on how stakeholders felt about the sad stories told by OVC, the following response came up from one of the teachers (CRS29):

I sympathize with the children. Though the African culture believes in extended family systems, many feel they are already overloaded with their own social and economic responsibilities and so may not be ready to assist. I feel churches, NGOs and individuals should be sensitized about the plight of OVC so that they become more willing to render help.

All the teachers and heads present had something of concern about the OVC situation and they wished people could work collaboratively to assist the children in good time. Another stakeholder (AUS23) said the following:

It is saddening given the fact that most of them are left out in programmes meant for them because patrons or leaders of such groups opt to assist people who may even be more privileged and fortunate than the ones in a $\mathrm{CHH}$.

The implication here was that the NAP for OVC should continue to make efforts to reach out to all OVC in 
Zimbabwe with basic services. This operation should be extended to the more needy cases that may not be known, even at the GoZ social welfare offices. Stakeholders suggested that schools should find time within their busy curriculum schedules to run awareness campaigns to allow more children to know about the documents that protect them. Both the NAP for OVC (2006-2010) and its child-friendly version should be known by all children, for no child knows when he or she may become an orphan.

In line with policy, the stakeholders were happy that the child-friendly version of the NAP's major focus was on education where plans were underway to give every child a chance to go to school. However, though the NAP for OVC (2006-2010) was developed to respond to the children's situation where resources seemed to be limited and still fragmented, some "hard-to-reach children" were in dire need of help, as noted by their voices presented in Theme 1. In response to such a claim, stakeholders suggested that the present policies and laws concerning OVC may be improved in some of the following ways in order to relieve the suffering minors. The recurring views were as follows:

- $\mathrm{CHHs}$ should be registered with both the social welfare and local government departments so that they are not missed when others received aid meant for OVC.

- All OVC in CHHs should get free medical care and free education unconditionally so that all their learning needs are facilitated in all ways possible.

- Policy should put all harsh offenders of OVC policy behind bars without bail.

- On distribution of resources, plans should be made clear at local level so that rightful OVC beneficiaries gain from the available resources.

So the general feeling of the stakeholders was that OVC should be helped and better protected. This stemmed from the Rapid Assessment, Analysis and Act Planning Process (RAAAPP, 2004) for OVC, a research study conducted in Zimbabwe in 2004, which suggested that the issue of OVC can be stressful and bound to be a great threat to the socioeconomic development of Zimbabwe. The issue of policy implementation was found to be stressful for implementers in a study by Maphalala (2006) in KwaZulu-Natal. Therefore stakeholders need to take heed if OVC's learning issues in $\mathrm{CHHs}$ are to be effectively monitored through policy. Perhaps it is high time that the Children's Act, Education Act, Maintenance Act and Child Abduction Act are fully known by all children and members of the community.

We noted that generally OVC and some teachers were not aware of the legislative measures meant to protect the child. It was anticipated that if all OVC were provided for there would be less stress and anxiety in their learning. In addition, the two national policies, that is the ZNOCP and the NAP for OVC, should get more publicity because they seem to reflect strengths about the traditional ways of caring for children at community level. The general feelings of the 14 stakeholders was that the ZNOCP's recognising the role of the traditional leader's role in caring for the underprivileged needs to be supported fully since it looks into marginalised groups, including OVC. A stakeholder (DRS30) added:

ZundeRaMambo should go beyond food security activities even up to receiving and distributing school fees on behalf of donor organizations, GoZ departments and church groups to the real needy OVC. There seemed to be misappropriation of the resources here and there in what should be gained by the real children in need of help. Some leaders tend to want to benefit their own clan children, even non-orphans.

Perhaps the stakeholder who believed the older traditional leaders who were well known by the communities were bound to be more impartial than the official distributors, who may be biased and may not know the really vulnerable child in need of help. The NAP for OVC's plea for qualitative researchers helps to hear the voices of the needy. However, from mere observation, the real OVC may want to be involved more in any further amendment, adjustments, corrections and so on of the policies that affect them. The 20 OVC the researchers worked with in Chipinge seemed to be less informed about the policies that may help them to exercise their rights as true citizens and children of Zimbabwe.

In commenting on the Education Act (Chapter 25:04), most of the stakeholders were glad that the tool is quite clear on its mandate to assist every learner to learn. They were very aware that among the learners who should be educated by 2015 (MDG 6) was OVC who required special guidance. The following excerpt from one school head (AUS1) confirmed the stakeholders' views that OVC should be considered in their education:

Policy should be much more practical and channel its focus towards helping the marginalized OVC especially in poorer districts such as Chipinge. The OVC should be fully involved in policy formulation and its implementation up to evaluation phases so that the child's needs are told and settled by the children themselves. Free education should be considered for the needy child, such as a vulnerable double orphan. 
The school head's pleas here coincided with Jinga and Ganga's (2011) research finding that education was not free for all unless one was enrolled under BEAM where a portion of the learner's fees was catered for. The issue of lack of fees was one drawback voiced by the 20 OVC involved in this research. BEAM funding may need other helpers to augment it because this study has noted from just the 20 OVC that the fund is overwhelmed, just as the NAC (Zimbabwe National AIDS Council 2011).

\subsection{Sub-category 2: Improving OVC academic preparedness}

In an effort to prepare OVC for educational or academic work in which we find learning and cognition, responses from the stakeholders on the open questionnaire indicated that most of the present interventions were concerned with satisfying the children's basic needs without much emphasis on the specifics for OVC education. Once BEAM paid fees, not much was mentioned about the few, but important, learning accessories that OVC requested. These included uniforms, shoes, pens, exercise books, readers, textbooks, satchels and stationery. At one school, it was disturbing to learn from a teacher (BRS26):

Even if UNICEF has made great strides to donate school textbooks, still there are some schools which are not yet ready to issue the books to the children because no parents have signed on their behalf, citing the fact that if the books are lost, no one will replace them.

The above excerpt was a clear indication that some school authorities required awareness about the presence of OVC, in particular double orphans, who did not have parents to act as sureties in instances such as the above. The above teacher reminded teachers to remain empathetic to OVC and provide necessary assistance when the children required it. A teacher can certainly sign on behalf of parents instead of denying OVC the opportunity to receive donated textbooks because they have no parents to sign on their behalf. As such books may remain unused in storage while the pupils have no textbooks to study so they can pass their examinations. Many more of the teachers were of the view that OVC should be treated in the same manner as all other children and be allowed to access textbooks. Another school head (CR27) mentioned that proper counselling and provision of the basic needs was essential as indicated by Maslow's hierarchy of needs (Mwamwenda, 2004). According to the literature, failure to attain basic needs hinders gratification of all other needs required by OVC. Teachers too should be prepared for the teaching and learning of OVC. The community should support all their activities. All the stakeholders believed that OVC should feel secure and welcome in their environment.

In the focus group discussions the children also raised the point that schools should recognise their presence by motivating them when they faltered. The children required reassurance that they had a chance to succeed in learning. Adults should be seen as good leaders who should help OVC pursue useful activities and also protect them from abusive adults. To the OVC, it seemed as if teachers did not fully appreciate the minimum effort OVC placed into their schoolwork. As such the teachers needed to be more responsive and show love and appreciation. The children reported teachers' and community failures to help OVC cope with grief and sometimes the stigma and discrimination they encountered in their efforts to learn well.

\subsection{Sub-category 3: Motivation for the child-parent}

The qualitative enquiry managed to identify various avenues in which stakeholders could further assist OVC. As a phenomenological enquiry based on participants' own views, the ways in which the school, community, NGOs, the GoZ and OVC could handle issues about motivation to learn in pupils from $\mathrm{CHHs}$. The literature reiterated that the OVC issue was every stakeholder's concern. The children urged local communities to suggest and implement ways that can motivate them to learn well. Among the numerous factors raised by the children was the need to identify the different children's learning styles and help them to cope. Learning materials that enhance learning in both urban and rural areas should be made available. The children also raised a plea about their inability to pay for extra lessons during the vacation and at weekends.

The school heads echoed the sentiments of all the teachers involved that OVC's learning difficulties were being perpetuated by their difficult life circumstances. They added that most OVC displayed learning difficulties across the curriculum, even with the assistance of occasional psychosocial counselling. Some extrinsic motivation was essential if the children were to become intrinsically motivated in their learning (Bruner in Skinner, 2009). One teacher firmly supported the children's plea for foster parents as an intervention strategy that could motivate learners at school. The 
children required parental care and guidance in the absence of their biological parents.

\title{
4.5 Sub-category 4: Emotional and psychosocial preparedness
}

According to the literature, cognitive, emotional and social capacities will shape an orphan's experiences throughout life. As significant others, teachers can help to tender hope and a life line that OVC trusted (Rutter, 2008). Teachers can easily remove the anxiety, the feelings of shame and guilt as well as doubt that OVC sometimes feel. Therefore the social environment can exert different influences on the child's emotional and psychosocial development. Asked how society may improve OVC's psychosocial preparedness to learn, the stakeholders unanimously agreed with one officer (US34) who said the following:

\begin{abstract}
Enhanced learning can help an OVC to trust and hope in good education so much that psychosocial difficulties in life can be eliminated once the child attains academic freedom. All that is required is for society to tender hope and empathy to the growing child until the OVC can become much more mature and independent. All that is required is resiliency on the part of the learner.
\end{abstract}

Research has established that poor children have self-writing tendencies that can make them resilient to pressures of orphanhood in poverty-stricken CHHs (Rutter's Pathway Model in Ganga \& Chinyoka, 2010). The self-writing tendencies were observed among many OVC who seemed to want to succumb to poverty because they were living in it. We noted that maternal deprivation especially among the many heading the $\mathrm{CHHs}$ had emotional instability as most of them showed fatigue, hopelessness and grief. The orphans manifested signs and symptoms of missing the security of a relationship with their parents. Evidence of such psychosocial difficulties was expressed through their developmental experiences.

The emotional instability among OVC could be eliminated through schooling (UNICEF, 2009) that allows learning and cognition to take place even in difficult life circumstances. The stakeholders concurred that learning can be possible if the children were assisted to cope with stresses in their developmental encounters. Resilience has been found to protect OVC from being overwhelmed by risk factors (Rutter, 2005). Most of what came from the 14 stakeholders was meant to encourage resilient behaviours around the life stressors that dominated in the CHHs. The life stressors have been noted as obstacles hindering learning and cognition of children in $\mathrm{CHHs}$. Cognition is vital to constructivism; once knowledge is constructed then it is learnt. Educators and the rest of the community members are, therefore, urged to work collaboratively to minimise the effects of orphanhood.

\section{Conclusions and Recommendations}

The researchers have read through the United Nations Convention on the Rights of the Child (UNICEF 2010). There seems to be some infringement of these rights, where the blame may not be necessarily centre on one stakeholder but on all adults in civic organisations. Like any other human rights, the child's rights need to be respected --- hence all should appreciate Mandela's dictum that there can be no keener revelation of society's soul than the way in which a nation treats its children (NAP for OVC, 2006-2010). The child's age should be considered when deciding on which right is right for each age group and which alternative can be ideal for orphan care. Parental guidance should, therefore, always accompany the child. Parents in Zimbabwe and other countries should plan well to avoid negative consequences for the child-parenting system.

Perhaps stakeholders should take heed of ideas raised by participants on OVC policy formulation and implementation where all stakeholders should be sensitive to OVC's living and learning situations. Children's cries for help mean they need to be involved with formulating the policies that affect them, especially the rural OVC who are hard to reach (NAP for OVC, 2006-2010). The rural OVC may have unique needs unknown to one in an urban environment. So there is a need to involve different backgrounds as the nation plans to assure the wellbeing of all minors. Many children, especially from within rural areas, were not properly aware of the policies that protect them --- if consulted they may voice their needs for action by the civic organisations in their areas. The numerous views raised by stakeholders require discussion, so as to chart a way forward for enhanced learning of affected OVC.

The messages from stakeholder data seem to confirm the RAAAPP (2004) finding within the literature review that the issue of CHHs may be a serious threat to socioeconomic development in Zimbabwe, hence the need for civil organisations to act swiftly. ZNOCP ideas about traditional leaders' roles seem noble, bearing in mind that if community leaders become aware of their parentless OVC, they may then become much more focused on directing aid to the 
needy. They all advocated a stress-free life for all OVC, hoping they may eventually be led to better learning and eventually free of their present hardships. This is in line with Rutter's $(2005,2008)$ idea of making a pathway on which all marginalised individuals can eventually rise above life's miseries. Therefore policy will help to talk to all advocates and non-advocates of children's rights in an effort to advance a better life line for OVC through quality learning.

The issues encompassed in policy planning on OVC seem centre on availing adequate resources for all OVC in the form of fees, as well as on learning resources found to be lacking or only minimally available. Preparing the learner fully for academic work becomes significant since it has been already noted that the school is the safest place for all children at risk. In fact, this study would also add that the school seems to be the child's place for finding peace and solace, because it is a place where children come together and share life experiences. The teachers and peers within the school are the shoulders on which OVC can cry on. This was evidenced by the responses established within the focus group interviews where all OVC seemed to appreciate the idea of having talking sessions for children facing the same predicament.

Based on the data received, several recommendations, grouped into four categories below, are listed for various stakeholders including OVC. The proposed comprehensive model below (Figure 2) tried to look into how a developing country such as Zimbabwe could enhance the learning of OVC from $\mathrm{CHHs}$. It summarises the four categories proposed as ways to enhance learning for OVC. It begins by identifying the needs (needs analysis) of the OVC learning situation summarised as monitored orphan care, empowerment of OVC, policy review editions and the need for continued OVC research. An implementation process (Maphalala, 2006) then follows in a step-by-step format as in Figure 2 below.

Figure 2: A proposed model for use in dealing with the plight of OVC

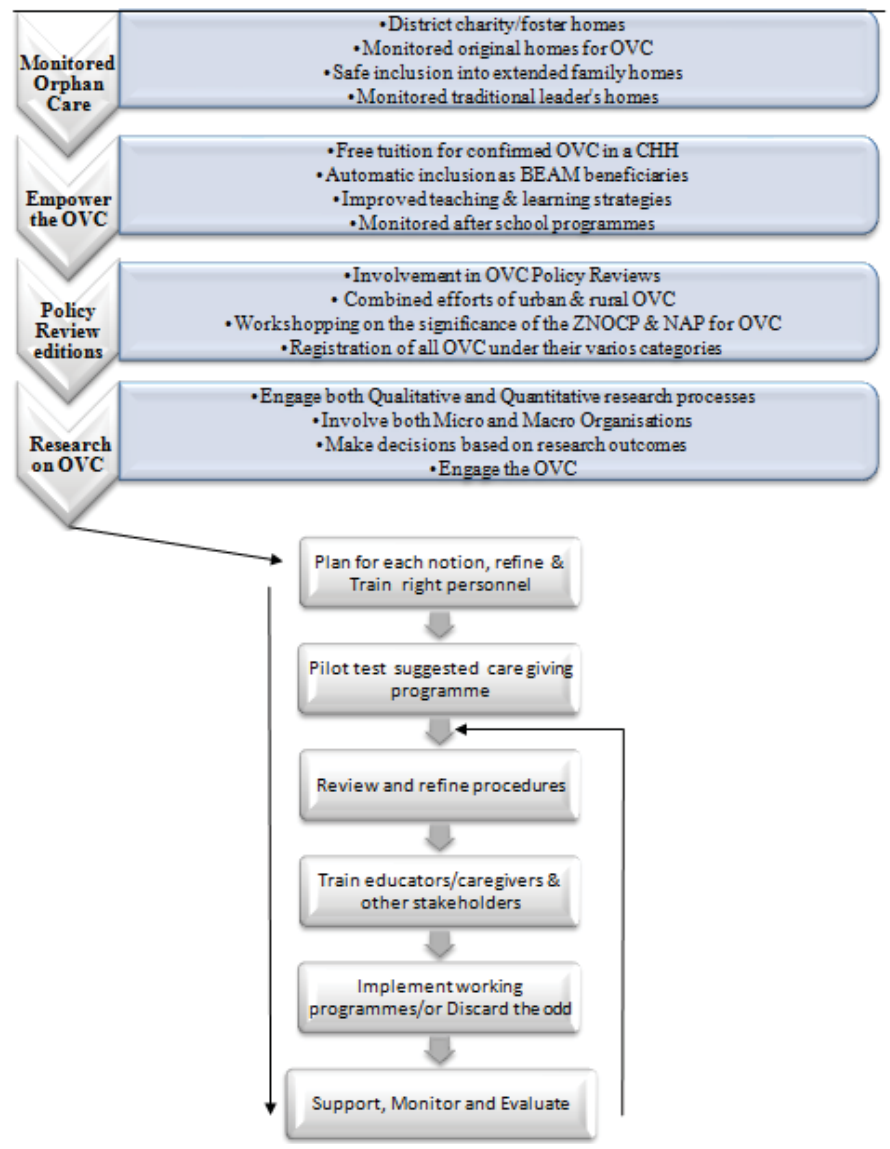


Further recommendations for policy formulation and implementation are as follows:

- Both government and nongovernment stakeholders should encourage formation of children's support groups in order to allow the young learners an opportunity to interact freely and separately from older people. In such support groups, OVC can then devote time to plan their own learning and avoid imposed learning policies that they may not find user-friendly. Perhaps it is also important to also assist OVC over the age of 18 because observations within $\mathrm{CHHs}$ noted that many OVC in the 19-22 year age range remained incapacitated.

- Civic organisations need to mobilise the population to provide both immediate and long-term support for OVC's learning, for example the best way to distribute BEAM or EFT funds so that the real sufferers gain.

- Policies that children formulate together with the policy makers should empower and protect them. Further training could be in areas of self-assertiveness, decision making and vocational training for more mature OVC, especially heads of $\mathrm{CHHs}$.

- The GoZ and civic organisations should set up child care centres to allow younger OVC an opportunity to receive emotional support without exposure to abuse and neglect. This gives an opportunity for older OVC to attend school every day.

- Food rations by NGOs and social welfare should be channelled through a stipulated protocol to avoid instances, mentioned by OVC, whereby names of beneficiaries for donor funding are transferred from one child to another without prior consultation between OVC and field coordinators of $\mathrm{CHHs}$.

- Respective government ministries should make sure that policies on inheritance and children's rights should be broadcast through workshops, conferences and NGOs, community members and relatives, cinema shows, posters and so on.

- The GoZ Ministry of Health and Child Welfare needs to find ways of monitoring the development of children in $\mathrm{CHHs}$, covering physical, social, emotional and intellectual development of children in order to plan interventions early enough.

- As much as possible, it is important to keep OVC from the same biological family together so that they can continue to express love, trust and care for one another.

\section{Acknowledgements}

We gratefully acknowledge the following groups and individuals who offered their consent and/or assent to participate in the research process: the Zimbabwe Ministry of Education, Sport, Art and Culture (from head office, through the provincial office, to the district office and then the selected schools), the Chipinge District Administrator's office, extended family members responsible for overseeing activities within the child-headed households, and the orphans and vulnerable children involved in this enquiry.

\section{References}

Chinyoka, K. \& Ganga, E. 2011. An exploration of psychological effects of poverty on child development in Ngundu in Zimbabwe. NAWA Journal of Language and Communication 4(1) 143-466.

Creswell, J.W. 2002. Research design; Qualitative, Quantitative; Mixed Methods Approaches. London: SAGE Publications Inc.

Creswell, J.W. 2007. Qualitative Inquiry and Research Design: Choosing Among five approaches London: SAGE.

Dakar Framework for Action. 2000. Education for All: Meeting Collective Commitments. (Online). Available at http://www.unesco.org/news/en/themes (Accessed on 18 July, 2011).

Ganga, E. \& Chinyoka, K. 2010. Psychological Disorders caused by Poverty among Orphans and vulnerable children in child headed households in Zimbabwe, Journal of Sustainable Development, Summer B, (12), (4), 186-196.

Jinga, N. \& Ganga, E. 2011. Effects of Holiday Lessons and Financial Pressure on Low Income Families and Households in MasvingoZimbabwe JETERAPS Scholar link 2 (6) 465-470.

Mahlomaholo, M.G. 2011. Gender Differentials and Sustainable Learning Environments. South African Journal of Education. Vol. 31, (3) 312-321.

Maphalala, M.C. 2006. Educator's Experiences in Implementing the Revised National Curriculum Statement in the GET Band (PhD Thesis) KwaZulu-Natal: University of Zululand.

Mavhunga, P.J. Madondo, M. \& Phiri, M. 2009. Education for all in Zimbabwe: A Mirage Zimbabwe Journal of Education Research Vol. 21 (1) 22-31.

NAP for OVC (National Action Plan for Orphans and Vulnerable Children). 2006-2010. Harare: Government of Zimbabwe.

NAP for OVC child-friendly version (National Action Plan for Orphans and Vulnerable Children: Child-Friendly Version). $2006-2010$. Harare: Government of Zimbabwe. 
O`Neil, V. 2011. Psychology: An Introduction. (3rd edition) Cape Town: Oxford University Press Southern Africa.

Plan GDD Finland. 2005. Available at http://www.orin.org/docs/resources/treaties/coc.40D/GDD 2005 Plan Finland.pdf. Accessed on 2 February, 2011.

Rapid Assessment, Analysis and Act Planning Process (RAAAPP). 2004. Harare: Government Printers.

Rubin, A. \& Babbie, E.R. 2010. Research Methodology for Social Work (6th Edition ) California: Thomson Brookes/Cole.

Rutter, M. 2005. How the environment affects mental health. The British Journal of Psychiatry 186 (4-6).

Rutter, M. 2008. "Implications of Attachment theory and Research for Child Care Policies" In Cassidy J. Shaver P, R. Handbook of Attachment Theory, Research and Clinical Applications. New York and London: Guilford Press pp 958-74.

Schram, T.H. 2006. Conceptualizing and Proposing Qualitative Research (2ndeds). Upper Saddle River, New Jersey: Pearson Education Inc.

Skinner, C.E. 2009. Educational Psychology. London: Blackwell Publishing Ltd.

UNAIDS. 2006. Report on the Global AIDS Pandemic: Geneva: UNAIDS.

UNESCO Dakar. 2000. Available on http:// www.unesco.org/news/en/edu/themes/leading- the- international-agenda/education-for-all/ Accessed on 29 January, 2012.

UNICEF. 2007. The State of World's Children 2007: Women and Children, the Double Dividend of Gender Equality. New York: UNICEF.

UNICEF. 2009. Promoting Quality Education for Orphans and Vulnerable Children: A Sourcebook of Programme Experiences in Eastern and Southern Africa, New York: UNICEF.

UNICEF. 2010. The Framework: Key Issues and Challenges. (Online). Available at http://www.unicef.org/aids/index-orphans.html. (Accessed on 12 February, 2012).

UNISA Policy on Ethics. 2007. Pretoria: Unisa Press.

Yin, R.K. 2003. Case Study Research, Design and Methods (3rd ed.) In Creswell, J.W. (2009). Research Design: Qualitative, Qualitative Methods Approaches. New York: Sage Publishers Inc.

Zimbabwe Demographic and Health Survey 2005 -2006 March. 2007. Harare: Central Statistical Office.

Zimbabwe Education Act 25: 04, 6/1991, 24/1994. Harare: Government Printers.

Zimbabwe Millennium Development Goals (MDGs), December, 2004 Progress Report, Harare: Government of Zimbabwe and UNDP.

Zimbabwe National AIDS Council (NAC). 2011. (Online). Available at http://www.infsw.org/p3000535.html. (Accessed on 25 January, 2011).

Zimbabwe National HIV and AIDS Strategic Plan (ZNASP). 2006-2010. National AIDS Council, Harare: Government Printers.

Zimbabwe National Orphan Care Policy (ZNOCP). 1999. Harare: Government Printers. 